\title{
EL GUION CINEMATOGRÁFICO: SU ESCRITURA Y SU ESTATUTO ARTÍSTICO
}

THE SCREENPLAY: ITS SCRIPTURE AND ITS ARTISTIC STATUS

\author{
Julia Sabina GUTIÉRREZ \\ Universidad de Alcalá de Henares \\ juliasabina.gutierre@uah.es
}

Resumen: Son muy diversas las teorías sobre la naturaleza y la función del guion. Ha habido directores que han filmado sus obras sin un guion previo y en muchos casos este texto ha sido considerado como un instrumento puramente auxiliar. En la actualidad el guionista se encuentra en una batalla para hacer valer su estatus como creador. En este trabajo se exponen las diversas opiniones sobre la función del guionista, sobre el carácter visual o literario de este género y sobre un receptor indeterminado de su trabajo ya que podemos preguntarnos si un guion tiene lectores o espectadores.

Palabras clave: Guion cinematográfico. Narratología. Nuevos Medios. Cine.

Abstract: There are many different theories about the nature and function of the screenplay. There have been directors who have filmed their works without a previous script and in many cases the screenplay has been valued as a purely auxiliary instrument. Currently the scriptwriter is in a battle to assert his status as a creator. In this work different opinions on the scriptwriter's function are exposed, as the visual or literary character of this genre and the indefinite receiver of his work since we can ask if a 
script has readers or spectators.

Key Words: Screenwriting. Narratology. New Media. Film Studies.

\section{EL ESTATUTO DEL GUION}

En los inicios del cine, cuando las funciones todavía no estaban bien definidas, algunos pioneros como Thomas Harper Ince se dieron cuenta de la importancia que tenía escribir la historia que iban a rodar, para poder controlar mejor los costes de producción de una película. A su vez, ha habido artistas que no han utilizado guiones -este es el caso de Buster Keaton-o que han filmado sus obras sirviéndose solo de notas, sin un guion real previo, como Jean-Luc Godard. De hecho, la función del guion en una película ha sido un tema controvertido durante muchos años, por cuestiones artísticas, pero también por motivos económicos. Este antiscreenwriting frame, como lo denomina el investigador Steven Maras (2009: 11), se apoya en la sospecha de que el guion aporta una dimensión literaria a la obra del realizador y lo aleja del lenguaje puramente audiovisual. Durante mucho tiempo ha habido cineastas que han considerado que rodar sin guion facilitaba la reflexión con imágenes.

En cuanto a las concepciones del guion, el Diccionario de la RAE lo define como un "texto en que se expone, con los detalles necesarios para su realización, el contenido de un filme o de un programa de radio o televisión". Isabelle Raynauld desarrolla estas ideas, insistiendo en sus aspectos literarios y fílmicos, y en su valor pragmático:

Le texte scénaristique se distingue du texte romanesque sur plusieurs points, notamment par sa double destination, textuelle et filmique, et surtout par sa valeur pragmatique. En effet, le texte scénaristique, comme le texte de théâtre, est avant tout déterminé par sa potentialité à être réalisé et tout dans le scénario sert, de manière implicite ou explicite, le futur film (Raynauld, 2012: 204).

El estatuto artístico del guion todavía no ha sido bien definido ni por los teóricos ni por los propios profesionales del audiovisual. 
Un guion presenta elementos formales semejantes a los de obra de teatro, pero, al contrario de lo que sucede en la obra dramática, el guion de una pieza audiovisual es un texto que todavía no ha sido reconocido y tiene una difícil inclusión en los géneros literarios.

Esto puede deberse a que el guion de cine y de televisión implica unas exigencias formales muy precisas. El guionista debe construir la historia y los diálogos, y describirlo todo con mucha minuciosidad para que sea reinterpretado por el realizador: escena interior o exterior, movimientos de personajes, día o noche, quién habla, qué edad tiene... Se trata de una escritura basada en la descripción de la imagen, objetiva y siempre en el tiempo verbal del presente (ya que no podemos ver nada en el pasado, vemos lo que vemos en tiempo presente, aunque sea un flashback). Estas circunstancias hacen que la lectura de un guion no sea tan fluida como la de una obra teatral o la de un texto narrativo. Otra razón que puede haber dificultado su estudio radica en que los lectores reales de un guion suelen ser muy reducidos, se limitan a las personas que participan en la creación de la película o de la serie televisiva, y el guion publicado no suele ser aquel sobre el que se ha trabajado sino uno reelaborado a posteriori.

Cuando se habla del guion del audiovisual se trata normalmente de la inferencia de una historia que nos han contado o que hemos visto representada. El guion que ha sido premiado en los festivales o comentado por la crítica es el fruto de esta abstracción. No nos encontramos frente a una obra literaria ni frente a una obra audiovisual; el guion es un elemento intermediario y aun así constituye las bases de la película, el mapa a seguir. Se trata de instrumento de trabajo que será escrito y reescrito, un proceso en el que pueden intervenir más de un guionista, directores, productores, censores...

Considerar el guion como un texto literario o un simple soporte de la imagen es objeto de tantas controversias como de las teorías y de los autores que las defienden. De la misma manera, podemos preguntarnos si un guion tiene lectores o espectadores. Como ya se ha explicado, el guion del audiovisual recibe la recepción por parte de un grupo bastante restringido de lectores, aquellos que intervienen en el transcurso del rodaje de un film, aunque una película sea vista por un numeroso grupo de personas (Viswanathan, 1999: 2).

Por ello, suelen plantearse las cuestiones siguientes: ¿dónde se encuentra el trabajo del guionista: en las palabras o en las imágenes 
filmadas? ¿Radica el guion en lo que vemos y oímos en la película, o en el texto publicado tras la distribución del filme? Son cuestiones que le llevan a Steven Maras a plantear cuál es el "object problema", ya que nos enfrentamos a dos dificultades al mismo tiempo: por un lado, definir el guion como objeto y, por otro, identificar un objeto para el guion, y se pregunta si es el guion el producto final del proceso guionístico o solo un aspecto más del proceso de realización de una obra audiovisual, o qué hacemos con las discrepancias entre el guion, la película y el guion distribuido a posteriori (Maras, 2009: 11).

De hecho, si como hemos explicado anteriormente, el guion se diluye en la película, ¿cabe plantearse la posibilidad de estudiar la obra de un guionista, como la de Rafael Azcona o de Jean-Claude Carrière. Es lo que ya se planteaban el mismo Carrière o Pier Paolo Pasolini (1966) cuando consideraban el guion como una estructura que tiende a otras estructuras. Nosotros estamos convencidos de que su estudio no solo es útil sino necesario, y en el mismo sentido se han pronunciado diversos investigadores en los últimos años, haciendo hincapié no solo en la naturaleza y en la función del guion sino también en el trabajo del guionista.

\section{EL GUIONISTA ¿TÉCNICO, CREATIVO O AUTOR?}

En esta época de eclosión de la ficción televisiva han surgido figuras como las de los creadores David Simon, J.J. Abrams, David Chase, que son garantía de calidad para los amantes de las series. Suelen ser guionistas que se encargan de que una serie se mantenga en una misma dirección creativa al constituir su producción y realización un proceso complejo y largo en el que interviene un gran número de profesionales. Y de este conjunto sobresale (he aquí la gran novedad que impone el apogeo y éxito de las series televisivas) el nombre del guionista en detrimento de la figura del realizador, algo impensable en el caso del cine. Este cambio de estatus del guionista como artista es el que nos ha lleva a interesarnos por la autoría del guion como eje imprescindible y modelador de la obra audiovisual en episodios.

Cuando se mantiene una conversación con un guionista, no es raro escuchar quejas relativas a las cuestiones de la autoría de los guiones, ya sea en las películas, series de TV o programas de entretenimiento en las que han trabajado y en los que muchas veces no aparecen citados ni en los 
títulos de crédito. "Yo escribí esto... no, fue el otro... me quitó la idea... lo reescribí todo yo..." son algunos de los comentarios habituales. De hecho, desde que la historia narrativa empezó a ser una prioridad en las películas, el escritor se ha visto enredado en un conflicto de autoría con el director, con otros guionistas y con el productor, y ha emprendido una batalla prácticamente quijotesca por su reconocimiento como experto, como artista y, en algunos casos, como director del control creativo.

¿Quién puede ser considerado como el verdadero autor de una obra artística, como es una película? Martin Heidegger, en sus reflexiones sobre la obra de arte, mantiene que el origen de algo es la fuente de su esencia. Es la obra la que hace al artista, y si el artista se distingue como maestro de un arte es gracias a su obra:

Pero ¿por medio de qué y a partir de dónde es el artista aquello que es? Gracias a la obra; en efecto, decir que una obra hace al artista significa que si el artista destaca como maestro en su arte es únicamente gracias a la obra. El artista es el origen de la obra. La obra es el origen del artista. Ninguno puede ser sin el otro (...) El artista y la obra son en sí mismos y recíprocamente por medio de un tercero que viene a ser lo primero, aquello de donde el artista y la obra de arte reciben sus nombres: el arte (Heidegger, 2010: 7).

Partiendo de estos postulados del filósofo alemán sobre la obra de arte, parece difícil poder hablar de un guionista como un artista (o un artista completo), dado que su obra está hecha para desaparecer, como indicaba Jean-Claude Carrière, y es la obra la que se supone que hace al artista, podemos preguntarnos si los guionistas son artistas sin obra. $\mathrm{O}$, dándole la vuelta a esta propuesta, ¿podemos decir que la obra audiovisual tiene un autor no definido o determinado? No es raro encontrar en la historia del séptimo arte ejemplos de cineastas que han ocultado el hecho de haber coescrito el guion de la película para ser considerados los autores de su obra.

La teoría de un autor individual es así frecuentemente criticada en los estudios sobre el guion, como los de Goldman (1984). Se considera que esta política es inapropiada para un complejo modo de producción industrial y que el uso del autor en el cine se utiliza de cara al marketing o 
que incluso puede llegar a ser una categoría ideológica (Maras, 2009: 97).

En La obra de arte en la época de la reproductividad técnica, Walter Benjamin reflexiona sobre el poder de la tecnología en la reproducción del arte y, en concreto, en el cine, medio que considera como su agente más poderoso. Para explicar su teoría, Benjamin describe la alienación del actor de cine oponiéndolo a la labor del actor de teatro: "El intérprete de cine no actúa ante un público sino ante un sistema de aparatos" (Benjamin, 2003: 68). Esta situación puede ser equiparable a la del guionista del audiovisual, porque su trabajo se muestra, igualmente, a través de una máquina. $\mathrm{Y}$, al igual que el actor de cine no es el mismo que el actor de teatro, el trabajo del guionista no puede equipararse al de un novelista o al de un dramaturgo.

Benjamin también señalaba cómo el sistema de división del trabajo capitalista estaba influyendo en el trabajo del actor:

El actor que se desenvuelve en el escenario se identifica con su papel. Al intérprete de cine, muy a menudo, esto le está prohibido. Su desempeño no es de ninguna manera unitario sino que está conjuntado a partir de muchos desempeños singulares (Benjamin, 2003: 69-70).

Asimismo, a medida que el cine ha evolucionado, el trabajo del guionista ha sido fragmentado y disgregado. No hay un único tipo de guionista, sino distintos con especialidades específicas: showrunners ${ }^{1}$, scriptdoctors $^{2}$, dialoguistas, argumentistas, etc. Al contrario que otras formas de producción literaria, el espacio del guion puede estar muy segmentado y sometido a lo que se denomina "división de la escritura", es decir, una escritura repartida entre creación y reescritura (Maras, 2009: 22). Por lo tanto, como el proceso creativo de la industria audiovisual implica la participación de numerosos trabajadores, puede caerse en la paradoja de analizar una "obra", sin saber quién es el autor de esta. El ejemplo de la televisión puede ser muy ilustrador a este respecto, ya que presenta muchos programas que raramente se atribuyen a un autor determinado ${ }^{3}$.

1. El Showrunner es la persona responsable del trabajo cotidiano en una serie. Está a cargo de mantener una dirección coherente en todos los aspectos de la serie.

2. El Script Docteur es un guionista que ha sido contratado para trabajar en un guion con problemas narrativos. Los Script Docteur no suelen aparecer en los títulos de crédito. Por consiguiente, es difícil saber si han intervenido.

3. El grupo de investigación CEISME (Paris III, Sorbonne Nouvelle) está investigando sobre la 
Además, encontramos distintas versiones de un mismo guion. Si tuviésemos entre las manos la versión final y definitiva (lo que en la industria es denominado como el Final Draft), podríamos constatar que muchas escenas, diálogos y personajes no aparecen como estaban escritos en el guion, ya que el texto que es publicado cuando la película ha tenido éxito suele diferir del que se utilizó durante el rodaje.

¿Tiene que ver la excesiva especialización con la muerte del artista? El investigador Nicols ve este fenómeno como un hecho necesario en las ciencias, ya que son campos difícilmente abarcables en su totalidad (Maras, 2009: 51). En este sentido Benjamin anticipaba que "en la grabación fílmica, ningún intérprete puede pretender una visión del conjunto del contexto en el que se encuentra su desempeño" (Benjamin, 2003: 70). El guionista también es partícipe junto a montadores, directores de fotografía, directores de arte... de este complejo proceso de producción.

En este mismo orden de cosas, podemos hablar del trabajo de numerosos artistas multimedia que colaboran modificando softwares libres o nuevas aplicaciones. Parece que los conceptos de obra y artista se difuminan ante unos medios de expresión cada vez más complejos. Al mismo tiempo que, paradójicamente, ha surgido la figura del videoartista que es polivalente y controla todos los aspectos creativos. Buenos ejemplos de ello son las figuras de Shirin Neshat o Bill Viola.

No obstante, y a pesar de todos los elementos y procesos que un autor no puede controlar en su trabajo en el cine, como serían el montaje o los efectos espaciales, su situación y distancia frente a la cámara, no llega a tal punto que no pueda reconocerse a un actor de talento. El maestro de guionistas españoles, Rafael Azcona, por ejemplo, logró transmitir a través de la pantalla un universo propio, personal, identificable por los espectadores desde su primera película, teniendo en cuenta, además, que Azcona ha colaborado con guionistas y directores con técnicas y procedimientos muy diferenciados, como Marco Ferreri, Carlos Saura o Luis García Berlanga.

En definitiva, como afirmaba Paul Valéry, los avances técnicos pueden trasformar tanto los modos de producción que pueden llegar a modificar la concepción misma del arte $^{4}$. ¿No modifica esto, por tanto, la

creación en televisión y se cuestiona el rol del creador televisivo.

4. "Nos Beaux-arts ont été institués, et leurs types comme leur usage fixés, dans un temp bien distinct du nôtre, par des hommes dont le pouvoir d'action sur les choses était insignifiant auprès de celui que 
concepción del artista? ¿Los trabajadores de la industria de los medios de comunicación de masas son creadores de una obra y, por lo tanto, artistas? ¿No vemos, sin embargo, emerger artistas con obras y obras sin artistas? O como reflexionaba Heidegger: "¿Acaso sólo hay obra y artista en la medida en que hay arte y que este es su origen? Sea cual sea la respuesta, la pregunta por el origen de la obra de arte se transforma en pregunta por la esencia del arte" (Heidegger, 2010: 7).

Por lo que se refiere al proceso de la obra de arte audiovisual, vienen distinguiéndose dos etapas: la de su concepción y la de su ejecución, una separación institucionalizada que divide la producción en fases (preproducción, rodaje, postproducción) y que introduce una lógica en la que resulta difícil ver la ejecución en términos de guion (Maras, 2009: 22). Los guionistas escriben primero y los realizadores ejecutan después lo que ellos han escrito sin prácticamente dialogar sobre la obra en sí misma. Esta es la situación ideal en una productora audiovisual; no obstante, a lo largo de la historia del cine muchas son las películas que han mezclado ambos procesos. Las anécdotas son infinitas. Un caso conocido es el de Casablanca (1942), cuyo guion se fue escribiendo a medida que se realizaba la película. Suele afirmarse que la enigmática interpretación de Ingmar Bergman se debía a que no sabía cuál era el final y a cuál de sus dos amores iba a elegir.

Actualmente, la evolución tecnológica está difuminando esta línea de separación entre la concepción de la historia y la ejecución, como por ejemplo a través de los efectos digitales que se utilizan para resolver problemas prácticos del film (George Lucas que está evolucionando de un proceso de rodaje en línea a uno por capas) o la realización de películas de animación en las que en ocasiones se va escribiendo el guion a medida que se realiza la película:

Digital filmmaking techniques not only potentially rework the separation of conception and execution, but also the

\footnotetext{
nous possédons. Mais l'étonnant accroissement de nos moyens, la souplesse et la précision qu'ils atteignent, les idées et les habitudes qu'ils introduisent nous assurent de changements prochains et très profonds dans l'antique industrie du Beau. Il y a dans tous les arts une partie physique qui ne peut plus être regardée ni traitée comme naguère, qui ne peut pas être soustraite aux entreprises de la connaissance et de la puissance modernes. Ni la matière, ni l'espace, ni le temps ne sont depuis vingt ans ce qu'ils étaient depuis toujours. Il faut s'attendre que de si grandes nouveautés transforment toute la technique des arts, agissent par là sur l'invention elle-même, aillent peut-être jusqu'à modifier merveilleusement la notion même de l'art" (Valery, 1934: 103-104).
} 
relationship betwen words and images and the nature of scripting itself (through animatics and pre-visualisations) (Maras, 2009: 22).

Para conciliar las exaltadas emociones de los guionistas y la "política de autor", Maras propone otra perspectiva de estudio, citando a Andrew Sarris, que asegura que existe una confusión entre las palabras autor-director, y considera la escritura y la dirección una actividad que se realiza dentro de un continuum. Sin embargo, considerar al director y al guionista como equivalentes plantea alguna dificultad porque si pensamos en el guionista como en un autor ¿por qué no considerar como autores a otros elementos significantes de un film, como el pintador o el director de fotografía, aparte del guionista? (Maras, 2009: 109).

Quizá en lugar de distinguir entre la concepción de una película (la fase de pre-rodaje) y su ejecución, se debería diferenciar entre la función de los creativos (guionistas), y la de los interpretativos (realizadores) (Maras, 2009: 112). Conviene, por tanto, analizar el texto del guion y su relación con el film, y explicar qué aportan, qué no aportan y en qué momento intervienen los guionistas.

\section{LA BÚSQUEDA DEL TEXTO PERDIDO}

Una visita rápida a la sección sobre el guion cinematográfico de una biblioteca nos permite ver libros dedicados a aspectos prácticos (Herman, 1951; Swain, 1976; Nash-Oakey, 1978; Seger, 1991; CarrièreBonitzer, 1991; Field, 1996), o a procedimientos técnicos (Nouet, 1957; Vale, 1993; Fernández Díaz, 1996; Chion, 2000) o al oficio del guionista (Goldman, 1992; Brady, 1995; Mamet, 1995; Quinquer, 2001). En este mismo sentido, las investigaciones sobre el guion pueden centrase en las estrategias discursivas (Sánchez-Escalonilla, 2001), sobre la trama de la obra (Tobías, 1999), sobre las bases de su escritura, la estructura o el estilo del guion (McKee, 1997; Rodari, 1998). Se han escrito "guiones modelo y modelos de guion" (Vanoye, 1996), y algunos investigadores se han centrado en cinematografías concretas, como las del cine clásico de Hollywood (Bordwell et alii, 1996 y Onaindía, 1996). Sin embargo, otros autores, como Jacqueline Viswanathan (1999) e Isabelle Raynauld (2012), han estudiado el guion como género narrativo en sí mismo, con los 
métodos de la narratología.

Para algunos, el guion pierde su razón de ser después del rodaje de una película. Sin embargo, a partir de los años 60 del pasado siglo empezó a despertarse un interés por este texto, y algunas editoriales comenzaron a publicar los guiones de aquellas películas que habían tenido gran aclamación del público o de la crítica. Viswanathan insiste en que los guiones publicados y reescritos, una vez que la película ha terminado, resultan de gran utilidad ya que pueden servir para el análisis de un film, pero también por su interés literario, que es el que se intenta resaltar en este trabajo:

Le scénario transcende alors sa vocation première. Comme la pièce de théâtre, il survit à la représentation et peut faire l'objet d'une lecture autre où le monde fictif se construit comme un spectacle dans l'imagination du lecteur (Viswanathan, 1986: 3).

De forma análoga, Isabelle Raynauld defiende que es la película la que hace uso del guion y que esta no lo completa, no lo acaba. Se realice o no la película, el guion continúa siendo, independientemente del filme, un material escrito: "le film se sert du scénario, il ne le complète pas, ne le finit pas [...] que le scénario soit ou non réalisé, il reste, indépendamment du film, un matériau écrit" (Raynauld, 1990: 204).

Si no resulta fácil definir el estatuto del guion, tampoco este texto presenta una estructura única, sino varias, como expone Bruno Maltais (2010):

a) La novelización, es decir, películas noveladas o ciné-romans, que son considerados como género literario.

b) La transcripción de una película, el texto escrito después de la realización del film; este texto busca reproducir por escrito lo que aparece en la pantalla.

c) El guion ficticio de un autor, de una película no realizada.

d) El guion cinematográfico publicado.

En el último caso, Maltais lleva a cabo una distinción entre los guiones realizados antes, durante o sin que el film haya sido realizado. Señala que 
los guiones escritos después de que la película se haya exhibido en las salas deben ser considerados como productos derivados: "Toutefois, si la version publiée est celle d'avant tournage du film, la publication de scénarios cinématographiques prend tout son sens" (Maltais, 2010: 149).

En la actualidad, diversos sitios de Internet están dedicados a la publicación de guiones, pero normalmente no indican en qué momento fue escrito el texto; todos estos guiones corresponden a películas que han sido ya rodadas.

Desde los inicios del cine, el guion ha pasado por múltiples formatos, desde textos cercanos a la dramaturgia literaria, a textos compuestos de dibujos o simples esquemas de la trama o la acción... Sin embargo, el carácter técnico del guion (un instrumento de trabajo para todo un equipo de especialistas) ha contribuido a que el guion se haya ido codificando. En la actualidad, las nuevas tecnologías que, por un lado, han dado instrumentos a los creadores multidisciplinares del audiovisual como los videoartistas, por otro lado, han contribuido a la estandarización de los formatos con la aparición de programas de software específicamente creados para la escritura del guion como Finaldraft o Celtx, que formatean el texto en estándares profesionales.

La división en escenas, la especificación de un decorado interior o exterior, la hora del día, la señalización de los personajes en mayúsculas, etc.... son técnicas que se utilizan para ayudar al productor a realizar el desglose de la película y el consiguiente plan de trabajo. Sin embargo, la escritura del texto también está codificada. Se distinguen, así, tres reglas o principios que deben tenerse en cuenta al escribir y leer un guion (Maras, 2009: 66):

- El guion marca el ritmo, ya que generalmente se entiende que una página de guion escrita representa un minuto de película.

- Se debe escribir en pequeñas frases más que escribir un párrafo de una página para relatar la ficción.

- Existen diferentes versiones del guion que van desde un de guion de presentación, a un guion de producción o el guion de rodaje. Estas distintas versiones de un mismo guion difieren en función de la información presentada. 
Además, al unir el espacio de la página con el tiempo en pantalla se expresa la velocidad de la acción. Una descripción minuciosa del espacio se traslada en un ritmo más lento, y las frases cortas se traducen en un ritmo más rápido. Así, si se detalla con minuciosidad un elemento, este procedimiento se traslada a un tipo particular de tamaño de plano. Además, términos como la utilización de la palabra "nosotros" pueden sugerir un punto de vista omnisciente más que uno subjetivo. Esta escritura del guion contribuye a la visualización mental de la película:

Rush and Baughman show how the reader is in a particularly important position in relation to the screenplay, since it is they who must interpret the relationship between camera and subject, and all the nuances of the relationship: the implied camera directions under the slug line (Maras, 2009: 73).

No es necesario en este caso incluir ángulos de cámara y direcciones técnicas, porque esto interrumpe la lectura; la puesta en escena se realiza a través del lenguaje y el ser capaz de trasladar esta propuesta visual mediante el discurso verbal será una de las características que diferenciará a un excelente guionista de uno normal. Esto era lo que quería explicar Pierre Maillot con esta aclaradora afirmación:

Que l'on écrive, par exemple: "Penché sur son bureau il écrivait nerveusement" ou: "sa main courait nerveusement sur le papier" ou: "on le distinguait derrière les rideaux, qui écrivait nerveusement penché sur son bureau”, il s'agit chaque fois du même personnage, du même lieu, de la même action, mais il est clair que trois plans visuels différents sont ici proposés (Maillot, 1989: 16).

Jacqueline Viswanathan desarrolla este proceso y aboga por un análisis menos inocente de las descripciones de los guiones: tratar un guion como un "texto visual sería demasiado fácil". Por otro lado

Certains scénarios sont loin d'être dépourvus d'intérêt 
au-delà de leur fonction pratique car ils proposent, plutôt qu'une description précise, détaillée et évocatrice, une lecture de la signification essentielle de l'image pour le spectateur (Viswanathan, 1986: 3).

Viswanathan también se refiere a una cierta subjetividad en el lenguaje atribuido a los guionistas, a pesar de su tecnicidad:

II est bien connu que les descriptifs de scénario relèvent dlun discours impersonnel où ne s'implique pas l'instance d'énonciation. Le scénariste se doit d'être clair et concis. II utilise volontiers des propositions nominales elliptiques. Cependant, il n'est pas juste d'affirmer que les descriptifs transmettent une approche totalement neutre et objective de la diégèse. Le texte reflète une certaine subjectivité, non-celle du narrateur-scénariste mais celle du spectateur. En d'autres termes, les descriptifs cherchent à restituer la perception toute particulière de la diégèse que donne le film, non seulement par les énoncés qui décrivent les angles de prise de vue et les mouvements de la caméra mais aussi par les énoncés descriptifs du contenu de l'image (Viswanathan, 1986: 79).

Se comprueba, así, que la lectura especializada y reposada de un guion revela una riqueza de imágenes y ritmos cinematográficos variados.

¿Qué obstáculos existirían, por tanto, para considerar el guion como literatura ya que, a pesar de todo, el guion es un texto escrito y los manuscritos son leídos y publicados? Sus técnicas son compartidas por la poesía y por la novela, se estructuran mediante diálogos y descripciones, como el teatro, y del mismo guion pueden filmarse distintas películas (Maras, 2009: 47). No obstante, Maras sostiene que el guion no es únicamente un trabajo artístico autónomo sino un "intermediate work", y esto no se debe únicamente a que la película la complete la cámara sino a que nunca hay una versión definitiva del guion; es un texto que cambia en cada etapa, constantemente: "There is never a definitive version of the screenplay of a film ; by definition it must related to the screenwork, but also by definition it cannot, as more work must precede the final outcome" 
(Maras, 2009: 48).

Es problemático, por tanto, intentar ver el guion fuera de su contexto de producción ya que en todos los casos resulta esencial la función del guionista y del resto de los que intervienen en la construcción de la película:

¿Se puede entonces conciliar la estructura incompleta del guion con la noción de un trabajo completo y acabado? Hay autores, como Gassner que insisten en la importancia del último guion escrito antes del rodaje porque: "By focusing on the 'final' shooting script Gassner is seeking and ideal authorative text, one that can be linked back to the authorial intention" (Maras, 2009: 56). Es decir, el guion final previo al rodaje será aquel que recoja la idea original antes de encontrarse con todos los problemas prácticos.

Un guion sirve como instrumento de trabajo a todo un equipo de profesionales durante la realización de una narración audiovisual; se trata de un texto que ha sido enriquecido y ha adquirido volumen gracias a la aportación de todo el equipo. Pero las páginas de este texto pueden ser modificadas por motivos no deseados, que tienen que ver con la industria, con la censura y con el contexto histórico. Es por ello por lo que lo que conviene considerar el guion "as a kind of blueprint, with production being modelled closely on the building of a house" (Maras, 2009: 22). Lo que, en cierto modo, nos remite a la tesis de Pier Paolo Pasolini (1966), según la cual, el guion es una estructura que tiende hacia otras estructuras.

En cualquier caso, conviene analizar la estructura del guion desde el punto de vista del discurso:

The discourse of screenwriting is constituted in the interaction and interference of different formations of creativity, narrative, industry and production, theory and practice. By analysing these formations, it is possible to get and insight into the way the industry is imaged and imagined by its practitioners (Maras, 2009: 23).

La complejidad de la estructura del guion y la influencia de los aspectos pragmáticos son, sin duda, algunos de los factores determinantes de la pluralidad de perspectivas con las que el guion ha sido abordado. Por ello, es importante tener en cuenta esta interacción entre creatividad e industria. 
De todas formas, resulta necesario considerar el guion desde su carácter de "intermediate work" para verificar de qué manera su escritura ha podido influir en la puesta en escena posterior del cineasta.

La naturaleza del guion es compleja, pero, aunque no se le haya asignado un género determinado, cada vez se resalta más su importancia por los investigadores de la teoría literaria y del cine, cada día se publican más guiones de películas y de series televisas, y no dejan de aparecer continuamente trabajos sobre la estructura y los modelos de guion.

\section{REFERENCIAS BIBLIOGRÁFICAS}

BORDWELL, D. et alii (1996). El cine clásico de Hollywood. Barcelona: Paidós.

BENJAMIN, W. (1973). Discursos interrumpidos, I. Madrid: Taurus. (2003). La obra de arte en la época de su reproductibilidad técnica. México: Ítaca.

BRADY, J. (1995). El oficio del guionista. Barcelona: Gedisa.

BRENES, C.S. (1987). Fundamentos del guion audiovisual. Pamplona: Ediciones de la Universidad de Navarra.

CARRIÈRE, J. C. (1997). "Una novela de aprendizaje". En El guion cinematográfico, D. Oubiña y G. Aguilar (eds.), 15-31. Barcelona: Paidós.

CARRIÈRE, J.C. y BONITZER, P. (1991). Práctica del guion cinematográfico. Barcelona: Paidós.

CHATMAN, S. (1990). Coming to terms. The retoric of Narrative in Fiction and Film. New York: Cornell University Press.

CHION, M. (1982). La Voix au cinéma. París: Éditions de l’Étoile. (2000). Cómo se escribe un guion. Madrid: Cátedra.

CLASCÁ, M. (1999). "Elementos técnicos para la escritura de guion". En Taller de escritura para televisión, L. Vilches (ed.), 125-148. Barcelona: Gedisa.

FEINMANN, J. P. (1997). "El contrato de la escritura". En El guion cinematográfico, D. Oubiña y G. Aguilar (eds.), 49-69. Barcelona: Paidós.

FERNÁNDEZ DÍAZ, F. (1996). Arte y técnica del guion. Barcelona: 
Ediciones de la Universidad Politécnica de Catalunya, TAC (Temes Audiovisuals i de Comunicació, n. ${ }^{\mathrm{o}}$ 3).

FIELD, S. (1995). El libro del guion. Fundamentos de la escritura de guiones. Madrid: Plot.

FILIPPELI, R. (1997). "Guion y filme: sobre la imposibilidad de la diferencia". En El guion cinematográfico, D. Oubiña y G. Aguilar (eds.), 185-195. Barcelona: Paidós.

GOLDMAN, W. (1992). Aventuras de un guionista en Hollywood. Madrid: Plot.

HAMILTON, I. (1990). Writers in Hollywood. New York: Carroll \& Graf. HEIDEGGER, M. (1993). El ser y el tiempo, 1927, trad. J. Gaos. México: Fondo de Cultura Económica. (2010). Caminos de bosque. Madrid: Alianza Editorial.

HERMAN, L. (1951). A practical manual of screenwriting for theatre and television films. New York: New American Library.

MALTAIS, B. (2010). Le phénomène des scénarios cinématographiques dans l'espace éditorial quebecois. Montréal: Université de Montréal.

MAMET, D. (1995). Una profesión de putas. Madrid: Destino.

MARAS, S. (2009). Screenwriting: History, Theory and Practice. London: Wallflower Press.

MCKEE, R. (1997). Story: Substance, Structure, Style and Principles of Screewriting. New York: Harper Collins. NASH, C. y OAKEY, V. (1978). The screnwriter's handbook.Writing for the movies. New York: Barnes and Noble Books.

NOUET, R. (1957). Comment écrire pour le cinema. Précis de technique du scénario. París: Agence littéraire du cinema.

ONAINDÍA, M. (1996). El guion clásico de Hollywood. BarcelonaBuenos Aires: Paidós.

OUBIÑA, D. y AGUILAR, G. (eds.). El guion cinematográfico. Barcelona: Paidós.

PASOLINI, P.P. (1966). “La lengua escrita de la acción”. En Comunicación I, 11-51. Madrid: Alberto Corazón Editor.

QUINQUER, Ll. (2001). El drama de escribir un guion dramático. Barcelona: Plaza \& Janés.

RAYNAULD, I., (2012). Lire et écrire un scénario: Le scénario de film comme texte. Paris: Armand Colin.

RÍOS CARRATALÁ, J. A. y SANDERSON, J. S. (eds.) (1996). Relaciones 
entre el cine y la literatura: el guion. Alicante: Universidad de Alicante.

RODARI, G. (1998). Gramática de la fantasía: Introducción al arte de inventar historias. Barcelona: Ediciones del Bronce.

SÁNCHEZ-ESCALONILLA, A. (2001). Estrategias de guion cinematográfico. Barcelona: Ariel.

SCHEUER, R.(1997). “Un arte instrumental”. EnEl guion cinematográfico, D. Oubiña y G. Aguilar (eds.), 71-79. Barcelona: Paidós.

SEGER, L. (1991). Cómo convertir un buen guion en un guion excelente. Madrid: Rialp.

STEMPEL, T. (1982). Screewriting. San Diego-London: AS Barnes and Co., The Tantivy Press.

SWAIN, D.V. (1976). Film script writing. A practical manual. New York: Hasting House Publisher.

TOBÍAS, R. (1999). El guion y la trama. Madrid: Ediciones Internacionales Universitarias.

TOROK, J.-P. (1986). Le scenario. Paris: Artefact.

VALE, E. (1993). Técnicas del guion para cine y televisión. Barcelona: Gedisa.

VALERY, P. (1934). Pièces sur l'Art. Paris: Gallimard.

VANOYE, F. (1989). Récit écrit-récit filmique. Paris: Nathan. (1996). Guiones modelo y modelos de guion. Barcelona: Paidós.

VILCHES, L. ed. (1999). Taller de escritura para televisión. Barcelona: Gedisa.

VISWANATHAN, J. (1999). “Ciné-Romans: Le livre du film”. Journal Cinémas 9.2-3, printemps, 13-36.

Recibido el 28 de mayo de 2017.

Aceptado el 5 de junio de 2017. 
